\title{
Mould and yeast identification in archival settings: Preliminary results on the use of traditional methods and molecular biology options in Portuguese archives
}

\author{
A.C. Pinheiro ${ }^{\mathrm{a}, *}$, M.F. Macedo ${ }^{\mathrm{b}}$, V. Jurado ${ }^{c}$, C. Saiz-Jimenez ${ }^{c}$, C. Viegas ${ }^{\mathrm{d}}$, J. Brandão ${ }^{\mathrm{e}}$, L. Rosado ${ }^{\mathrm{e}}$ \\ ${ }^{a}$ Departamento de Conservação e Restauro da Faculdade de Ciências e Tecnologia da Universidade Nova de Lisboa, Portugal \\ ${ }^{\mathrm{b}}$ Vicarte, Departamento de Conservação e Restauro da Faculdade Ciências e Tecnologia da Universidade Nova de Lisboa, Portugal \\ ${ }^{\mathrm{C}}$ Instituto de Recursos Naturales y Agrobiologia, CSIC, Sevilla, Spain \\ ${ }^{\mathrm{d}}$ Escola Superior de Tecnologias de Saúde de Lisboa, Instituto Politécnico de Lisboa, Portugal \\ ${ }^{\mathrm{e}}$ Unidade de Referência de Doenças Sistémicas e Zoonoses do Departamento de Doenças Infecciosas do Instituto Nacional de Saúde Doutor Ricardo Jorge, IP, Lisboa, Portugal
}

\section{A R T I C L E I N F O}

\section{Article history:}

Received 14 September 2010

Received in revised form

4 February 2011

Accepted 4 February 2011

Available online 12 April 2011

\section{Keywords:}

Fungi

DHPLC

Archives

Paper documents

\begin{abstract}
A B S T R A C T
This project was developed to fully assess the indoor air quality in archives and libraries from a fungal flora point of view. It uses classical methodologies such as traditional culture media - for the viable fungi - and modern molecular biology protocols, especially relevant to assess the non-viable fraction of the biological contaminants. Denaturing high-performance liquid chromatography (DHPLC) has emerged as an alternative to denaturing gradient gel electrophoresis (DGGE) and has already been applied to the study of a few bacterial communities. We propose the application of DHPLC to the study of fungal colonization on paper-based archive materials. This technology allows for the identification of each component of a mixture of fungi based on their genetic variation. In a highly complex mixture of microbial DNA this method can be used simply to study the population dynamics, and it also allows for sample fraction collection, which can, in many cases, be immediately sequenced, circumventing the need for cloning. Some examples of the methodological application are shown. Also applied is fragment length analysis for the study of mixed Candida samples. Both of these methods can later be applied in various fields, such as clinical and sand sample analysis. So far, the environmental analyses have been extremely useful to determine potentially pathogenic/toxinogenic fungi such as Stachybotrys sp., Aspergillus niger, Aspergillus fumigatus, and Fusarium sp. This work will hopefully lead to more accurate evaluation of environmental conditions for both human health and the preservation of documents.
\end{abstract}

(c) 2011 Elsevier Ltd. All rights reserved.

\section{Introduction}

Cultural heritage - particularly books and documents - have recently been the focus of examination for fungal contamination. In our written heritage, fungi have been consistently isolated using the traditional culture methods (Zyska, 1997; Corte et al., 2003). The time needed to ensure complete development of fungi on a growth medium varies from a few days to 30 days in some cases, and although this is still the most common method of identification in clinical samples, some fungal species cannot be cultured. According to Muyzer and Smalla (1998) 99\% of all microorganisms in nature cannot be isolated and, therefore, identified under a microscope, or they show a very slow growth rate and/or very special media requirements. Many fungi from the Ascomycete group and the majority of Basidiomycetes do not grow on standard laboratory

\footnotetext{
* Corresponding author. Tel.: +351 212948322; fax: +351 914089433

E-mail address: catmarpin@gmail.com (A.C. Pinheiro).
}

media (Salvaggio and Aukrust, 1981) and therefore the identification of these fungi can only be achieved through molecular biology methods. Moreover, when compared to traditional culturing methods, not only do these allow the identification of non-culturable microorganisms that may have caused deterioration in the past, but they also enable the identification of cell debris, which can be responsible for allergic reactions in those in contact with these documents (Wlazlo et al., 2008). Although molecular biology methods drastically reduce the time needed to perform a laboratory identification of fungi colonizing an ancient document, when the task is to analyze a mixed fungal sample (population), these modern techniques are still quite laborious - a problem that derives solely from the presence of more than one fungus.

In this paper, a very recent analytical method is introduced denaturing high- performance liquid chromatography, or DHPLC which, once optimized, will allow the retrieval and separation of fungal DNA from a mixed sample in just 20 min per run. The basics on which it relies are known and applied in DGGE, but the simplicity and speed of the process are greater in DHPLC. In both, 
similarly sized yet differently sequenced DNA fragments can be separated according to the decreased electrophoretic mobility of a partially melted double-stranded DNA molecule. DGGE uses polyacrylamide gels containing a linear gradient of DNA denaturants (Muyzer and Smalla, 1998) and DHPLC uses an ion-pair reverse phase HPLC column and an organic solvent (acetonitrile, from here onwards designated as eluent $B$ ) for the DNA elution. While DGGE is effective in many ways, it is both time-consuming and laborious, as the attempt to unveil the identity of the individuals present in a particular microbial community involves the process of cloning prior to sequencing. The more recent DHPLC is now starting to be applied in the field of human health genetics, and herein we describe its basic application to resolve complex fungal mixtures found in archival settings. Another protocol also applied in this work makes use of the automated fluorescence sequencer, here used to ascertain the identity of yeast colonies present in a mixture through the use of characteristic ITS2 length. This project's goals were to bring insight to the fungal flora found on archives - air, surfaces, and documents - and explore DHPLC and fragment length analysis as molecular biology options to better achieve this goal.

\subsection{Methodological options in molecular biology}

There are many molecular biological methods currently in use for the genetic identification of fungi. Polymerase chain reaction is basic to them all but, once the DNA is extracted, one can choose different ways to proceed. Sequencing the PCR product has been one of the most promising methods for the molecular identification of fungal DNA. There are several possible regions for amplification (see Fig. 1), each with its advantages and disadvantages.

The amplified region should, ideally, be sufficiently conserved amongst fungi in order to allow the amplification of several genera. However, it should also be variable enough to allow discrimination between closely related species. The $18 \mathrm{~S}$ region evolves relatively slowly and is considered universal for fungi, i.e., it can be used to find consensus conserved regions within a group of fungi and to detect them, but it is not divergent enough to provide a distinction between them (Ninet et al., 2003). There is still no consensus on what region to amplify in order to achieve the best identification scores: Ribosomal targets such as the ITS1-5.8S-ITS2 or the LSU (25S-28S) are strong contenders in this challenge.

The D1-D2 region (in the LSU) has been exploited extensively (Abliz et al., 2004) with very good results in terms of GenBank identification scores, partially because there is a large contribution in this region and the database is, hence, very large. Because this is not the case with the ITS regions, the D1-D2 is sometimes used to confirm ITS1 or ITS2 results (Cano et al., 2004; Leaw et al., 2006). Nevertheless, and according to Hinrikson et al. (2005), the current identification of some Aspergillus species, especially those closely related, is best achieved using the ITS query sequences rather than the D1-D2 regions of the $25-28 \mathrm{~S}$ region of the genome. Also, ITS has recently been established as the bar-coding region of excellence (Rossman, 2007) as part of the European Consortium for the Barcode of Life initiative maintained by the Centraalbureau voor Schimmelcultures (CBS) and, therefore, an enrichment of the ITS region sequence database is to be expected. The comparison between these two regions in the identification of the fungi found in ancient documents is one of the most important aspects of this work, and since they complement each other they will both be put to use.

In clinical research, once the best sequence for a correct identification has been chosen and the protocol optimized one has merely to proceed to the sequencing part. Since in the case of archives we are not dealing with clinical samples - where there is a low probability of infection by more than one fungus - we need to find a way to separate the amplified DNA from a mixture of origins in order to be able to sequence each one. Nowadays this is usually done with DGGE and cloning. Although DGGE offers the advantage that individual bands can be excised, re-amplified, cloned, and sequenced, many methodological difficulties, such as co-migration of bands with similar sequences, double or multiple bands from identical sequences, formation of chimeric and heteroduplex molecules, and limited phylogenetic information from sequenced bands, are usually encountered in the analyses (Janse et al., 2004; Gafan and Spratt, 2005; Nikolausz et al., 2005). In addition, one band may not necessarily represent one species and one bacterial/fungal species may also give rise to multiple bands because of multiple 16S rRNA genes with slightly different sequences (Gelsomino et al., 1999).

Denaturing high-performance liquid chromatography has recently emerged as an alternative to this method and has already been applied to bacterial communities (Domann et al., 2003; Barlaan et al., 2005) and mixed Candida samples (Goldenberg et al., 2005). As with bacterial samples, the microscopic approach to fungal identification lacks the discriminating capacity for the assessment of a community's diversity, especially in complex populations, and DHPLC is set to overcome this problem with results obtained in a matter of minutes. This technology allows the identification of each component of a mixture based on their genetic variation, as submitting the amplified double-stranded DNA to an appropriate temperature leads the strands to partially denature. The right interaction between the ion-pairing reagents and the cartridge matrix allows the different components of the mixture to be eluted at different times. In a highly complex mixture of microbial DNA this method can be used simply to study the population dynamics or the effects of human action over a population - as the introduction of antifungal substances. What we will be attempting, however, goes beyond the community monitoring analysis as a whole, as this system also allows the sample fraction collection, which can, in many cases, be immediately re-amplified and sequenced, circumventing the need for cloning. Regarding the technique's setbacks, its resolution (as happens with DGGE) may not yet be sufficient, as DHPLC peaks may represent comigrating amplicons from different bacterial species (Goldenberg et al., 2007).

Denaturing high-performance liquid chromatography can be run in two basic methods depending on the temperature: nondenaturing or partially denaturing. At non-denaturing conditions $\left(50{ }^{\circ} \mathrm{C}\right)$, the amplicon is fully double-stranded and DNA separation is based solely on fragment size and is independent of sequence.

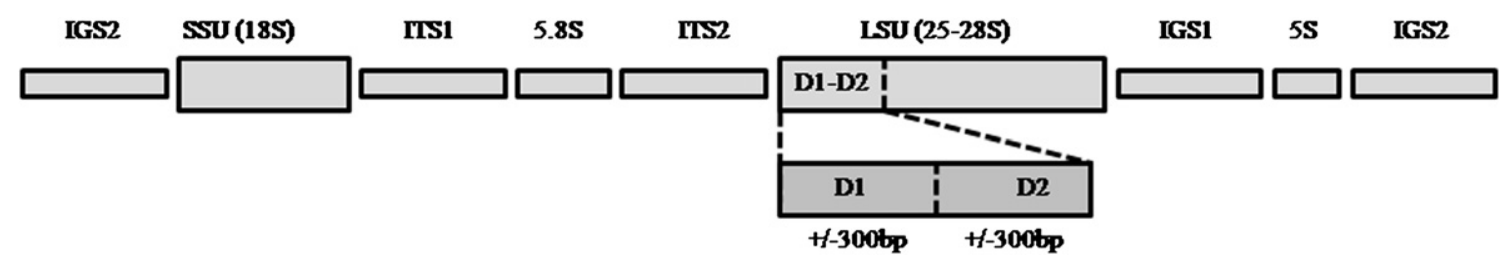

Fig. 1. Schematic representation of DNA regions in the fungal genome. IGS = intergenic spacer; ITS = internal transcribed spacer; LSU = large subunit; SSU = small subunit. 
Sizing results are similar to results obtained from an agarose gel and PCR products can be checked for purity.

The use of non-denaturing temperatures and a potential specific time of retention for each species could lead us to believe possible the creation of a size database and the use of these size differences as an identification marker. The already mentioned ITS2 region $(+/-300 \mathrm{bp})$ is highly variable between different species (Turenne et al., 1999) and some authors assert (Turenne et al., 1999; De Baere et al., 2002) that its length variation alone can serve as an identification marker. ITS2 size determination has already been used successfully in the identification of Candida species using automated fluorescent capillary electrophoresis (AFCE), a method also being applied in this study but to the identification of culturable yeast colonies present in a mixture. However, when applied to a complex mixture of filamentous fungi - and given the universe of species one can find in the environment - it will be relatively easy to find different taxa with the same amplicon length, a fact that renders this technique insufficient (Fujita et al., 2001; Hinrikson et al., 2005).

When using partially denaturing temperatures in dHPLC $\left(>50^{\circ} \mathrm{C}\right)$, size and sequence play a role in defining the elution time. Fig. 2 illustrates the usefulness of the technique as a mixture of three fungal species of known origin, Alternaria alternata (Scientific Institute of Public Health, Brussels), Aspergillus niger (from the Quality in Water Analysis Scheme quality test), and Penicillium spinulosum (from the RINGTEST quality test), all of them amplified for the D2 region, are submitted to a DHPLC program at $57{ }^{\circ} \mathrm{C}, 59 \%$ buffer $\mathrm{B}$ at a $0.9-\mathrm{ml} \mathrm{min}^{-1}$ flow rate. These fungi were selected because Alternaria sp., Penicillium sp., and Aspergillus sp. are common paper contaminants (Zyska, 1997).

At partially denaturing temperatures the column/eluents will separate DNA according to sequence (GC content) and molecular conformation, which is a very useful complement to the size difference mentioned above and follows the same idea of DGGE.

Given the choice of possible genomic regions one has still to consider a DHPLC limitation: The longer the fragment, the harder it is for the DHPLC system to identify the differences in the sequences analyzed, and so the method is most precise for sequence fragments of no more than $500 \mathrm{bp}$. This reason supports our choice of using two different fragments to accurately identify the fungal components of our mixtures: ITS2 from the ITS region and the D2 part of the D1-D2 genomic region. This way, both sequences studied will have an average 300-bp length. Regarding the D2

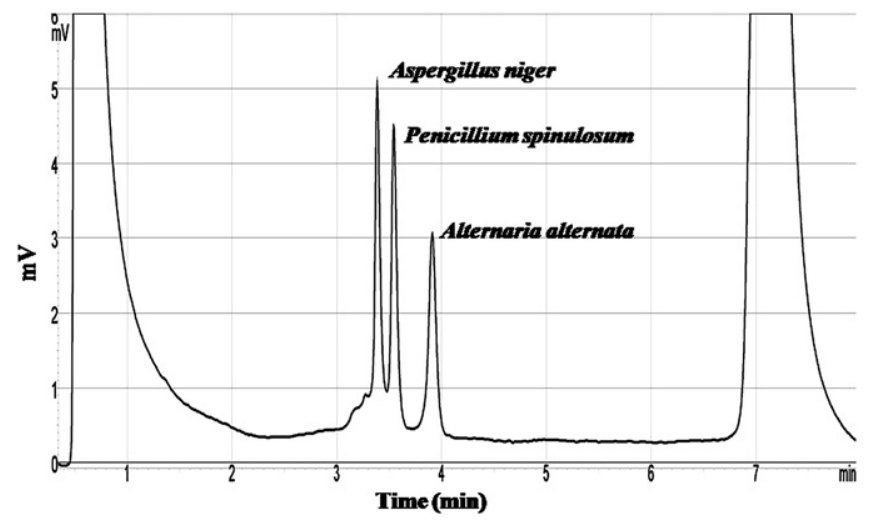

Fig. 2. DHPLC chromatogram of a mixture of amplified DNA from three different fung (Alternaria alternata, Aspergillus niger, and Penicillium spinulosum). The amplified products are 298 base pair in length and the mixture of the three provides a simple peak when run at $50{ }^{\circ} \mathrm{C}, 40 \% \mathrm{~B}$. The figure above was a result of the following conditions: temperature $-57{ }^{\circ} \mathrm{C}$; wave optimized buffer B (acetonitrile)-59\%; DNASep Cartridge $0.9 \mathrm{ml} \mathrm{min}^{-1}$. The targeted region was D2. region, when compared to the 600-bp D1-D2 region, the size reduction is not expected to bring any deficit in the quality of the sequence in terms of identification scores since this smaller region is targeted by commercial kits such as the MicroSeq D2 LSU 28S Fungal Identification and Sequencing kits from Applied Biosystems, with very good discriminating power (Ninet et al., 2003).

\section{Materials and methods}

\subsection{Sampling protocol}

As stated earlier, culturing methods cannot and should not be excluded from any fungal analysis - be it in an environmental sample or in an ancient piece of paper. This is especially relevant when trying to assess the impact a fungal population can have on human health, which is also one of the objectives in archive studies.

In terms of determining the fungal presence in documents (and document covers), sampling was performed in three archives situated in the area of Lisbon and one in Evora, a smaller city located in a different climatic and urban setting. Because we were dealing with valuable artwork the protocol related to document sampling was developed around a non-invasive swab sample. For DNA extraction, however, best results are achieved whenever small fragments of the document can be removed without damaging the document itself. The cotton swab from the paper samples retrieves material to use in the molecular biology protocol and in the following culturing media (Samson et al., 2004): malt extract agar (MEA) + chloramphenicol, dichloran-glycerol (DG18) (for xerophilic fungi) and mycobiotic agar (MA) (Larone, 2002) - especially conceived for the development of dermatophytes. All of these inoculated media (original and duplicate) were placed in an incubator set to $27^{\circ} \mathrm{C}$, and they remained there for a week (MEA) or 15-20 days (MA and DG18). The identification was based on the microscopic visualization $(400 \times)$ of morphological characteristics using lactophenol cotton blue dye and illustrated manuals (Larone, 2002; Samson et al., 2004)

Because fungi are not only important biodegradation agents for the books and documents housed in archives but are also known allergens (Mandrioli and Caneva, 1998), air samples were also retrieved during the sampling period of this study (using an M Air Tester, Milipore, Massachussets, USA). To establish a trustworthy assessment of the environmental health conditions of the chosen archival rooms, the dust settled in the shelves/working tables and floor was also sampled (Buttner and Stetzenbach, 1993; Maggi et al., 2000; Duchaine and Mériaux, 2001). Whenever they are considered relevant, other surfaces may also be analyzed. These environmental samples are, for the time being, analyzed only through traditional culturing methods. The yeast colonies obtained in these media, however, were analyzed through AFCE, using the ITS2 length as a marker for species identification.

\subsection{Molecular biology protocols}

Regarding the swabbed sampled paper (or the small fragments of documents), the DNA from the samples was collected and stored in a 300- $\mu \mathrm{l}$ TNE solution ( $1 \mathrm{ml} 1 \mathrm{M}$ Tris- $\mathrm{HCl}, \mathrm{pH} 8+2 \mathrm{ml} 5 \mathrm{M}$ $\mathrm{NaCl}+0.2 \mathrm{ml} 0.5 \mathrm{M}$ EDTA, pH $8+96.8 \mathrm{ml}$ distilled $\mathrm{H}_{2} \mathrm{O}$ ) at $-70^{\circ} \mathrm{C}$. For the DNA extraction the High Pure DNA Template kit from Roche (Mannheim, Germany) was used. To ease the DNA retrieval from all the fungi present in the gauze cotton swabs, some minor alterations to the protocol were made, including the use of $2-\mathrm{mm}$ and $4-\mathrm{mm}$ glass beads and a cell disrupter (FastPrep-24, MP Biomedicals, Solon, Ohio) with a very strong mechanical action over the samples. The extraction protocol was also applied to a negative sample of TNE solution. 
Two DNA regions were mentioned earlier: 28S and ITS. Both regions are considered good starting points for sequencing and identification but, for one of the methods selected in this project (DHPLC), the fragment size obtained when amplifying ITS1 and ITS2 and the entire D1-D2 region would result in a very large fragment-too large for the resolution needs of this study as shown earlier. The chosen fragments-ITS2 and D2-are about 300 bp in length.

The database for automated fluorescent capillary electrophoresis is being generated by clinical and environmental strains of fungi isolated at the Portuguese National Institute of Health. These are harvested and diluted in sterile water followed by DNA extraction using the aforementioned DNA extraction kit. The DNA obtained is amplified for the ITS2 region using ITS4 and ITS86HEX primers and a protocol described in Turenne et al. (1999), to which some changes were made, namely the absence of the dUTP in the reaction mix. This database will be the key to the identification of the yeast(s) present in each of the growth plates mentioned in the sampling protocol.

For the DHPLC and the ITS2 fragment length analysis the DNA was amplified as indicated in Table 1.

All amplifications were performed in a MyCycler Thermocycler (BioRad, California, USA) and two negative controls (for amplification and extraction) were included in every amplification. After the PCR procedure, the amplification products were checked in electrophoretic $2 \%$ agarose gels stained with SybrSafe (Invitrogen, California, USA) and visualized under UV light. For sequencing purposes ExoSap-IT (Affymetrix, California, USA) was used for PCR purification and the resulting product was then submitted to a sequencing program. For the ITS2 region, $1 \mu \mathrm{l}$ amplified DNA was added to 2.0 pmol primer (ITS3 or ITS4), $3.5 \mu$ l Sequencing Buffer $5 \times$, and $0.5 \mu \mathrm{l}$ Big Dye Terminator Ready Reaction v1.1 in a $10-\mu 1$ mix. The sequencing protocol consists of 25 cycles of $96^{\circ} \mathrm{C}$ for $10 \mathrm{~s}$, $54{ }^{\circ} \mathrm{C}$ for $5 \mathrm{~s}$, and $60{ }^{\circ} \mathrm{C}$ for $4 \mathrm{~min}$. For the MicroSeq protocol, the purified DNA was separated in two tubes: the forward reaction, containing $7 \mu \mathrm{l}$ of PCR reaction product and $13 \mu \mathrm{l}$ of the forward mix and the reverse reaction, using the same amounts but with the reverse mix. Both were submitted to the sequencing program: 25 cycles of $96{ }^{\circ} \mathrm{C}$ for $10 \mathrm{~s}, 50{ }^{\circ} \mathrm{C}$ for $30 \mathrm{~s}$, and $60{ }^{\circ} \mathrm{C}$ for $4 \mathrm{~min}$ (Table 2).

The resulting sequence was then aligned with ClustalX and matched with the GenBank NCBI database (http://blast.ncbi.nlm. nih.gov/Blast.cgi).
Table 2

ITS2 fragment length (base pairs) of selected yeast strains. This value is an average and will be updated as more samples are being tested. The standard deviation (SD) obtained for each average value is in brackets.

\begin{tabular}{lll}
\hline $\begin{array}{l}\text { Yeast } \\
\text { (number of isolates tested) }\end{array}$ & $\begin{array}{l}\text { ITS2 length fragment } \\
\text { (average number of basepairs) }\end{array}$ & $\begin{array}{l}\text { Standard } \\
\text { deviation }\end{array}$ \\
\hline Candida albicans (10) & 283.02 & 0.51 \\
Candida glabrata (18) & 364.36 & 0.47 \\
Candida kefyr (15) & 376.31 & 0.39 \\
Candida krusei (7) & 287.68 & 0.51 \\
\hline
\end{tabular}

\subsection{DHPLC analysis protocol}

\subsubsection{DHPLC optimization}

The elution of the samples depends on a series of factors such as column temperature and buffer B gradient rate, and so conditions have to be optimized. The example given in Fig. 3 was a result of a series of tests on temperature, buffer gradient, and rate of flow. The separation began to occur at $57{ }^{\circ} \mathrm{C}$ and $59 \% \mathrm{~B}$ but other combinations $\left(59{ }^{\circ} \mathrm{C}, 55 \% \mathrm{~B}\right)$ also resulted in a good definition of the three peaks (data not shown). However, to optimize the protocol for future samples, several fungal species were selected and their ITS2 and D2 sequences were analyzed by the Wave (v.4) DHPLC sequence analyzer program. A predicted temperature was automatically selected by the Wave program and it was around this suggestion that a range of analytical temperatures was chosen (between 59 and $63^{\circ} \mathrm{C}$ ): Since the collected samples will present an unknown composition just one temperature would not cover all the possibilities in terms of fungal presence. As with the D2 region (see Fig. 2), it is possible to use the ITS2 region to separate the components of a mixture and the following example, Fig. 3, is an illustration of that.

For both amplicons, the program used was the double-stranded single fragment and the elution buffer acetonitrile. The column used was the DNASep ${ }^{\circledR}$, made from alkylated nonporous polystyrene-divinylbenzene (PS-DVB) copolymer microspheres for high-performance nucleic acid separations. The negative and positive amplification controls were included in every run.

For some of the samples currently under study a series of tests still have to be performed to ensure the best resolution. The reason behind the choice of flow rate lies in the proximity of the peaks and in the difficulty of separating them for collection. A higher flow rate produces a quicker run and sharper peaks, which makes them more

Table 1

PCR conditions for the D2 region and ITS2 region amplification.

\begin{tabular}{|c|c|c|c|c|}
\hline Amplification & Primers & PCR Program & & PCR mix \\
\hline ITS2 & $\begin{array}{l}\text { ITS3 (forward) (White et al., 1990): } \\
5^{\prime} \text { GCATCGATGAAGAACGCAGC 3' } \\
\text { ITS4 (reverse)(White et al., 1990): } \\
5^{\prime} \text { TCCTCCGCTTATTGATATGC 3' }\end{array}$ & $\begin{array}{l}95^{\circ} \mathrm{C}, 5 \mathrm{~min} \\
95^{\circ} \mathrm{C}, 30 \mathrm{~s} \\
54{ }^{\circ} \mathrm{C}, 1 \mathrm{~min} \\
72^{\circ} \mathrm{C}, 1 \mathrm{~min} \\
72^{\circ} \mathrm{C}, 6 \mathrm{~min}\end{array}$ & $35 \times$ & $\begin{array}{l}\text { Buffer } 10 \times: 5 \mu \mathrm{l} \\
\mathrm{MgCl}_{2} 25 \mathrm{mM}: 6 \mu \mathrm{l} \\
\text { DNTPs } 100 \mathrm{mM}: 0.5 \mu \mathrm{l} \\
\text { Taq polymerase } 5 \mu / \mu \mathrm{l}: 0.25 \mu \mathrm{l} \\
\text { Primers } 100 \mu \mathrm{M}: 2 \times 0.25 \mu \mathrm{l} \\
\text { DNA template: } 20 \mathrm{mg}\end{array}$ \\
\hline ITS2 & $\begin{array}{l}\text { ITS86-hex (forward) (Turenne et al., 1999): } \\
\text { 5' GTGAATCATCGAATCTTTGAAC 3' } \\
\text { ITS4 (reverse) (White et al., 1990): } \\
5^{\prime} \text { TCCTCCGCTTATTGATATGC 3' }\end{array}$ & $\begin{array}{l}94{ }^{\circ} \mathrm{C}, 10 \mathrm{~min} \\
94{ }^{\circ} \mathrm{C}, 30 \mathrm{~s} \\
55^{\circ} \mathrm{C}, 30 \mathrm{~s} \\
72{ }^{\circ} \mathrm{C}, 1 \mathrm{~min} \\
72{ }^{\circ} \mathrm{C}, 10 \mathrm{~min}\end{array}$ & $30 \times$ & $\begin{array}{l}\text { Buffer } 10 \times: 5 \mu \mathrm{l} \\
\mathrm{MgCl}_{2} 25 \mathrm{mM}: 6 \mu \mathrm{l} \\
\text { DNTPs } 100 \mathrm{mM}: 0.5 \mu \mathrm{l} \\
\text { Taq polymerase } 5 \mu / \mu \mathrm{l}: 0.25 \mu \mathrm{l} \\
\text { Primers } 100 \mu \mathrm{M}: 2 \times 0.25 \mu \mathrm{l} \\
\text { DNA template: } 20 \mathrm{mg}\end{array}$ \\
\hline $\begin{array}{l}\text { MicroSeq D2 LSU rDNA Fungal } \\
\text { Identification kit (Applied Biosystems) }\end{array}$ & not discriminated & $\begin{array}{l}95^{\circ} \mathrm{C}, 10 \mathrm{~min} \\
95^{\circ} \mathrm{C}, 30 \mathrm{~s} \\
53^{\circ} \mathrm{C}, 30 \mathrm{~s} \\
72{ }^{\circ} \mathrm{C}, 1 \mathrm{~min} \\
72{ }^{\circ} \mathrm{C}, 10 \mathrm{~min}\end{array}$ & $35 \times$ & $\begin{array}{l}15 \mu \mathrm{l} \text { Master Mix } \\
15 \mu \mathrm{l} \text { DNA }\end{array}$ \\
\hline
\end{tabular}




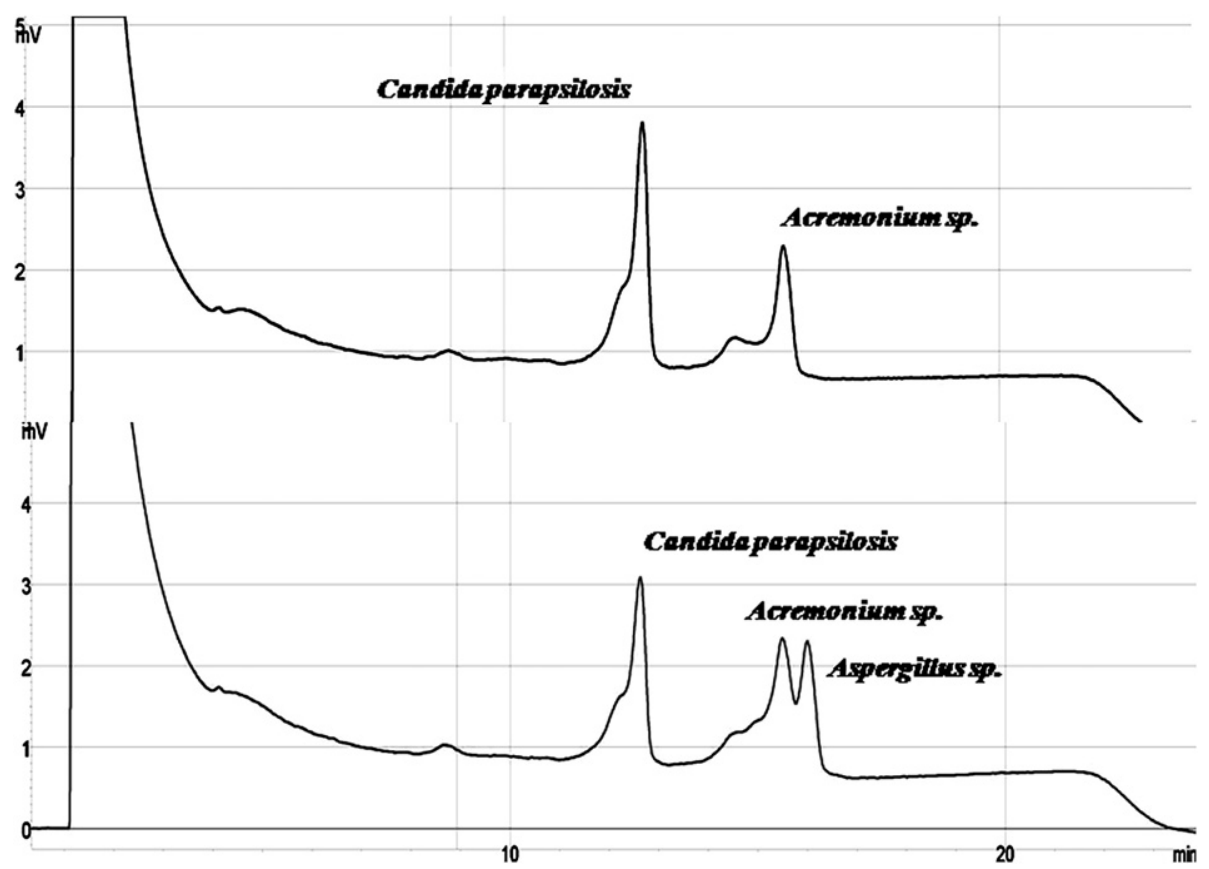

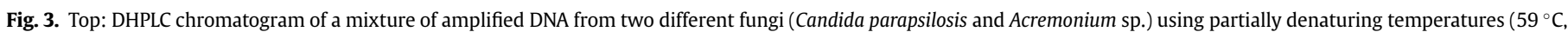

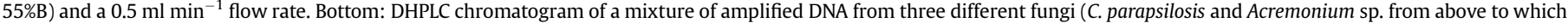
Aspergillus sp. was added) using the same conditions as above. In this example, the amplified region is the ITS2.

easily identifiable but, when they are too close, more difficult to collect. In this case it is best to choose a slower flow rate.

In the fieldwork, once real mixed samples are collected, extracted, and amplified together they are first run on the DHPLC at $50{ }^{\circ} \mathrm{C}$ to check the quality of the amplified product; they are then rerun through the column at the temperature range mentioned above. Peak collection allows the retrieval of the amplified DNA, which can then be sequenced.

In the absence of an automated collector it is possible to collect the peaks manually, an option tested previously by the authors. The sample represented in the chromatogram peak elutes a few seconds before the peak is visible on-screen. After collection it is not necessary to perform any subsequent steps before amplification and sequencing. Because this technique has rarely been applied to

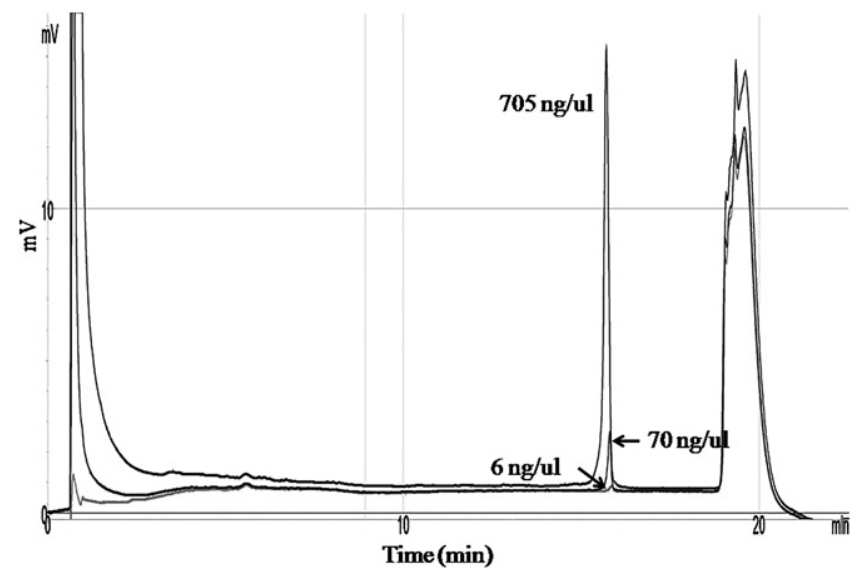

Fig. 4. Detection limits for the DHPLC DNASep Cartridge. A pure Candida parapsilosis D2 region amplicon (300 bp) was used to perform this test and the minimal amount of DNA detectable by the device was $5 \mathrm{ng} \mu^{-1}$. The program used was non-denaturing at $50{ }^{\circ} \mathrm{C}, 40 \% \mathrm{~B}, 0.9 \mathrm{ml} / \mathrm{min}$. fungal communities the use of both ITS2 and D2 will minimize possible losses of information from the technique itself and from the fact that we are only using a 300-bp sequence to achieve identification.

\subsubsection{DHPLC performance tests}

In order to establish this limit, a yeast sample amplified DNA amount was determined using a Nanodrop 2000 (Thermo Scientific, Massachussets, USA). The initial Candida parapsilosis sample had $705 \mathrm{ng} \mu \mathrm{l}^{-1}$ and the $1: 10$ and 1:100 dilutions amounted to 70 and $6 \mathrm{ng} \mu \mathrm{l}^{-1}$, respectively. All three samples were run on DHPLC sizing program $\left(50{ }^{\circ} \mathrm{C}, 40 \% \mathrm{~B}\right.$, flow rate $\left.0.9 \mathrm{ml} \mathrm{min}^{-1}\right)$. The DHPLC is able to detect a PCR product with DNA amounts higher than $5 \mathrm{ng} \mu^{-1}$ (see Fig. 4).

The performance of a single species (in this case, $C$. parapsilosis) at several temperatures was also tested. This was necessary to

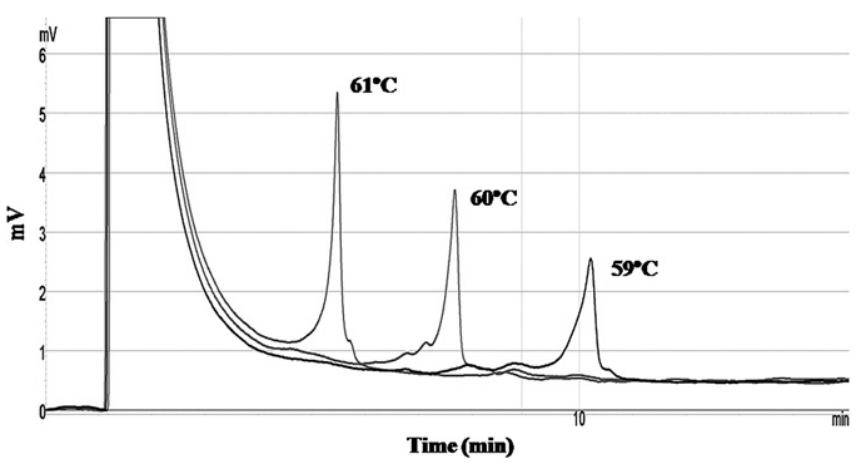

Fig. 5. Performance of a single species at partially denaturing temperatures. This test was performed with a culture collection Candida parapsilosis and the partially denaturing temperatures were $59{ }^{\circ} \mathrm{C}(55 \% \mathrm{~B}), 60^{\circ} \mathrm{C}(51.2 \% \mathrm{~B})$, and $61{ }^{\circ} \mathrm{C}(54.2 \% \mathrm{~B})$. The rate of flow used was $0.5 \mathrm{ml} \mathrm{min}^{-1}$. For this species $61{ }^{\circ} \mathrm{C}$ was the maximum temperature possible, as higher temperatures resulted in elution of the peak at the beginning of the run (the peak did not appear on-screen). 


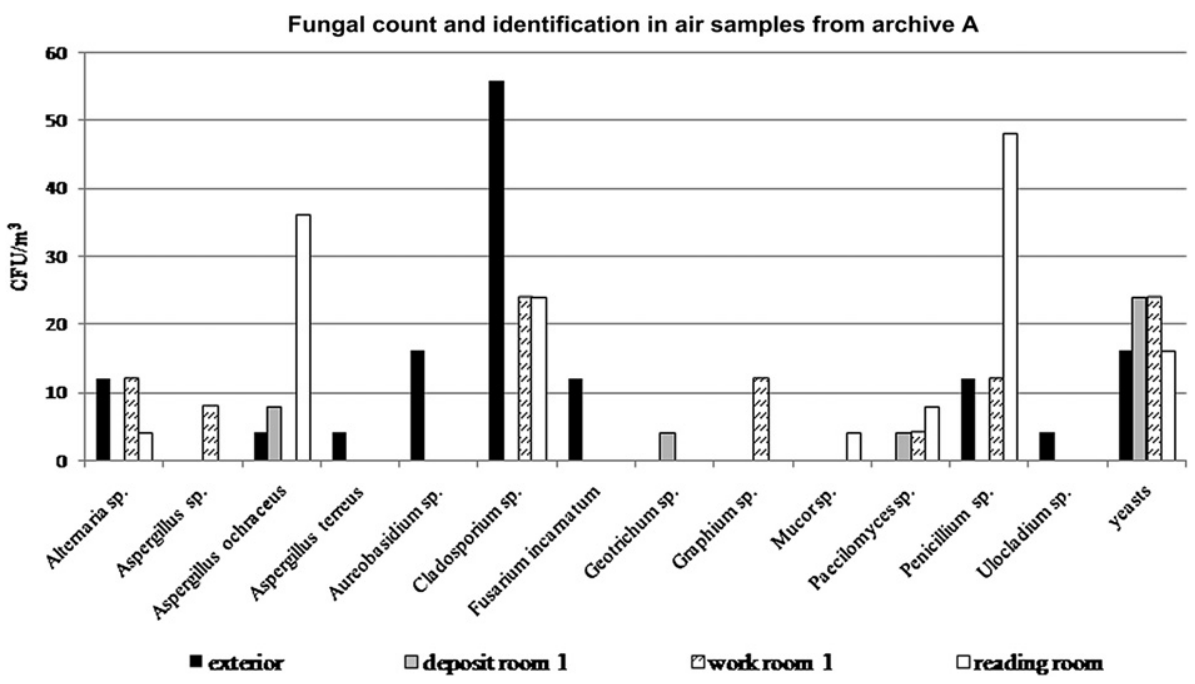

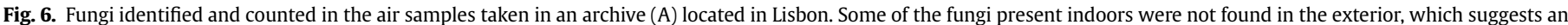
interior contamination.

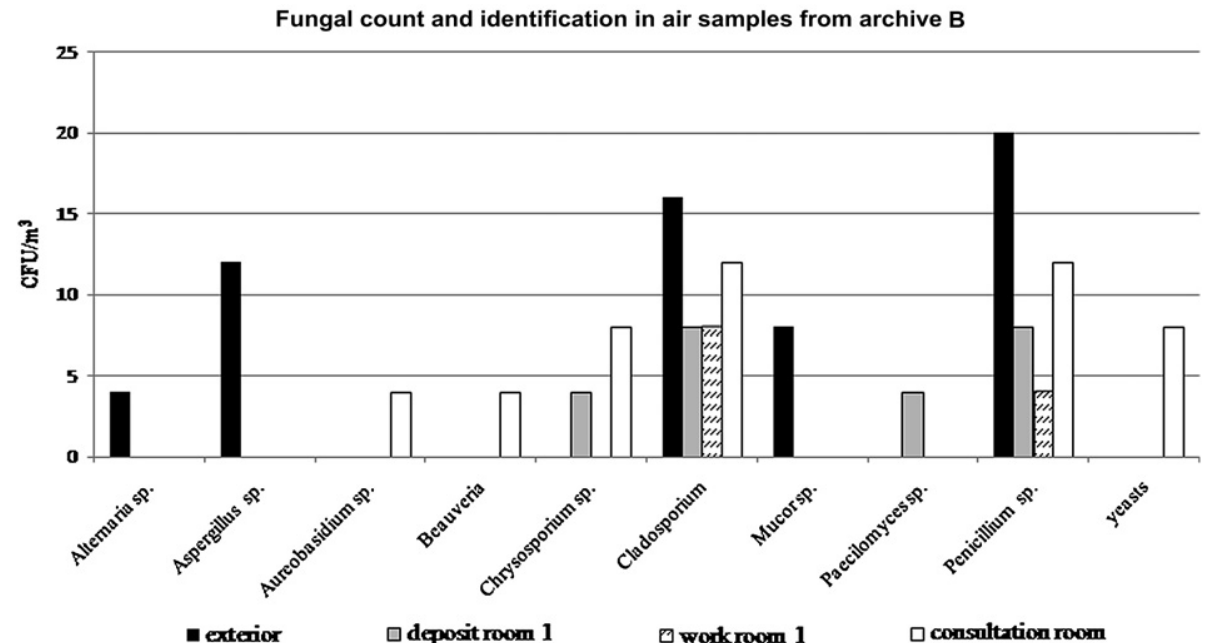

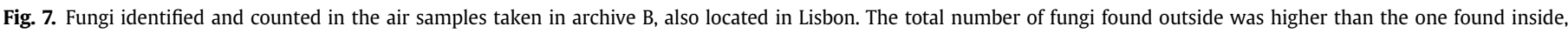
which suggests a quality environment. Nevertheless, some fungi identified inside were not present outside, which denotes contamination from within.

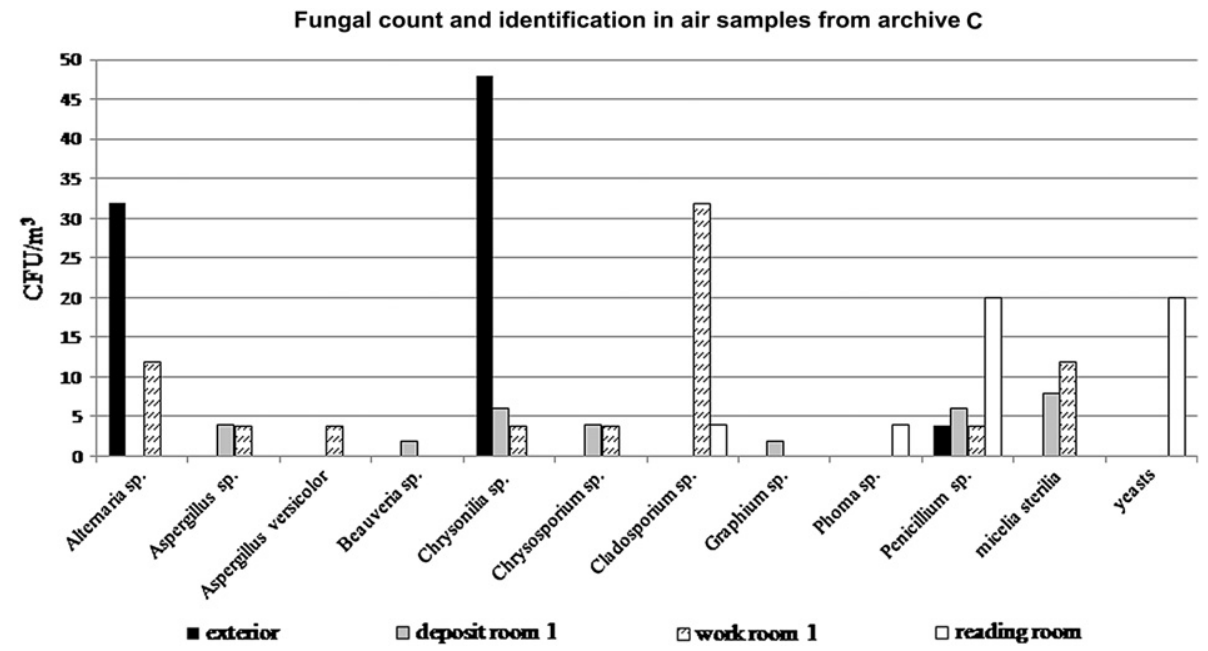

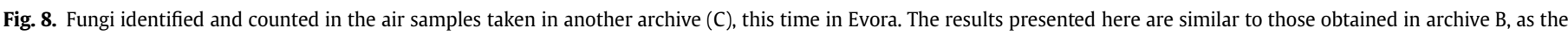
fungal contamination inside was lower than that outside, although the interior had some fungal genera not present in the exterior sample. 
guarantee that when working with a single species one only obtains one peak at partially denaturing temperatures (see Fig. 5).

\subsection{Automated fluorescent capillary electrophoresis system}

The capillary electrophoresis apparatus used was the ABI Prism 3130XL Genetic Analyser (Applied Biosystems, California, USA). One $\mu \mathrm{l}$ of the PCR product was added to the electrophoresis mixture ( $0.5 \mu \mathrm{l}$ of the ROX-500 marker and $10 \mu \mathrm{l}$ of deionized formamide). The samples went through a denaturation step for $3 \mathrm{~min}$ at $95{ }^{\circ} \mathrm{C}$ and the sample injection was carried out at $5 \mathrm{kV}$ for $15 \mathrm{~s}$, followed by an electrophoresis at $60{ }^{\circ} \mathrm{C}$ and $15 \mathrm{kV}$ for $30 \mathrm{~min}$.

To create the database all runs were done in triplicate. When compared with the databank presented in Turenne et al. (1999) our results show a slight deflection toward a higher base pair number (about 4 bp difference). This difference can be attributed to the sequencer itself since we use the ABI Prism 3130XL (Applied Biosystems, California, USA), and in the cited article the device used is the ABI Prism 310 Genetic Analyser (also from Applied Biosystems). These differences have already been discussed in the literature (de Baere et al., 2002).

\section{Results}

\subsection{Fungal analysis from media cultures}

So far only one season has been sampled (winter 2010) but the results obtained showed an indoor prevalence of common fungi such as Penicillium spp. and Cladosporium spp., both in air and surface samples. Regarding the less common genera, we were able to isolate species such as A. niger, Aspergillus fumigatus, Aspergillus versicolor, Fusarium spp., and Stachybotrys sp., all of which have a strong impact on human health because they can act as pathogens or/and produce secondary metabolites capable of inducing toxic responses.

According to Portuguese legislation (Nota técnica NT-SCE-2, 2009), in terms of microbiological standards, the presence of certain genera/species of fungi is considered possibly dangerous: Stachybotrys chartarum (S. atra), Fusarium spp., A. versicolor, Aspergillus flavus, A. fumigatus, A. niger, Histoplasma capsulatum, and Cryptococcus neoformans.

In terms of indoor air quality regulation (Nota Técnica NT-SCE-2, 2009), the total number of fungal elements found inside should be

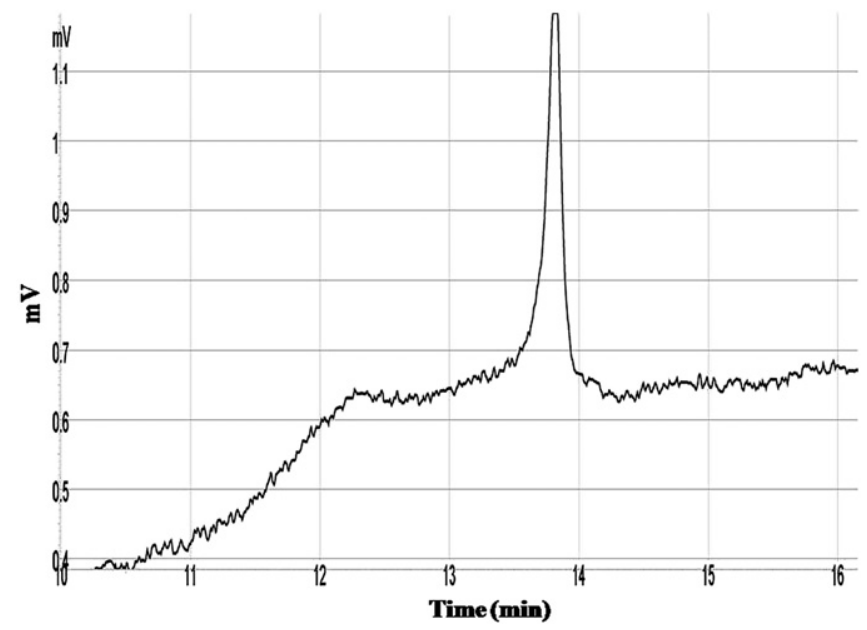

Fig. 9. DHPLC chromatogram of a swab sample from a document showing the presence of fungal DNA. The DHPLC allows peak collection and this procedure was done from minute 13 to minute 14 .The amplified region was D2 and the run was performed

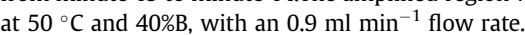

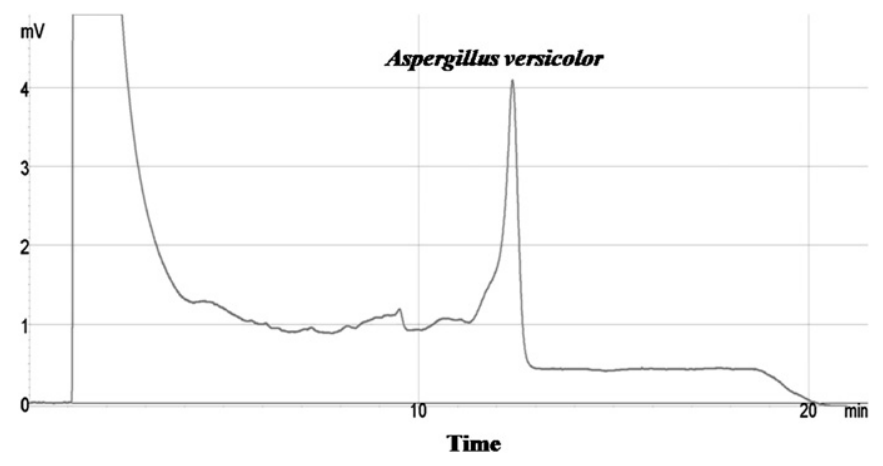

Fig. 10. DHPLC chromatogram of the sample depicted in Fig. 9, after peak collection (minute 13) and now under partially denaturing temperature $\left(59{ }^{\circ} \mathrm{C}\right.$ ) and $55 \% \mathrm{~B}$, with a $0.5 \mathrm{ml} / \mathrm{min}$ flow rate. Only one peak appeared and the sample was collected again (minute 12/13) and sequenced. The result was Aspergillus versicolor.

less than what is found outside, but this was not true for all cases studied (reading room in archive A (Fig. 6) presented a higher fungal count than the one registered outside, $140 \mathrm{cfu} \mathrm{m}^{-3}$ versus $136 \mathrm{cfu} \mathrm{m}^{-3}$, respectively). Although this was not the case with archive B or C (Figs. 7 and 8), when the analysis was performed for fungal species there were fungal elements present inside that either were not found outdoors or were present in lesser amounts, suggesting fungal contamination from within (Kemp et al., 2003). This can happen as people and books or documents can enter these archives and contribute to a different indoor fungal population. This was especially visible in archive C, where only three of the 12 species/genera found indoors were also present outdoors. The exterior sample in this more rural setting can be very different from the one found in Lisbon (archives A and B), but another factor possibly accountable for this difference is the presence outside of Chrysonilia spp., a very fast-growing fungus that covers the plate very rapidly and does not leave room for other fungi to develop. This is probably the reason Aspergillus spp. or Cladosporium spp. were not isolated in the exterior sample taken in Evora. These data will be the subject of further scrutiny as more samples are being processed, but the two examples given illustrate some of the issues addressed in terms of air quality in archives.

From a conservation point of view it is important to know the resident communities in archives and libraries because these can contribute greatly to the document's biodeterioration. Fungi such

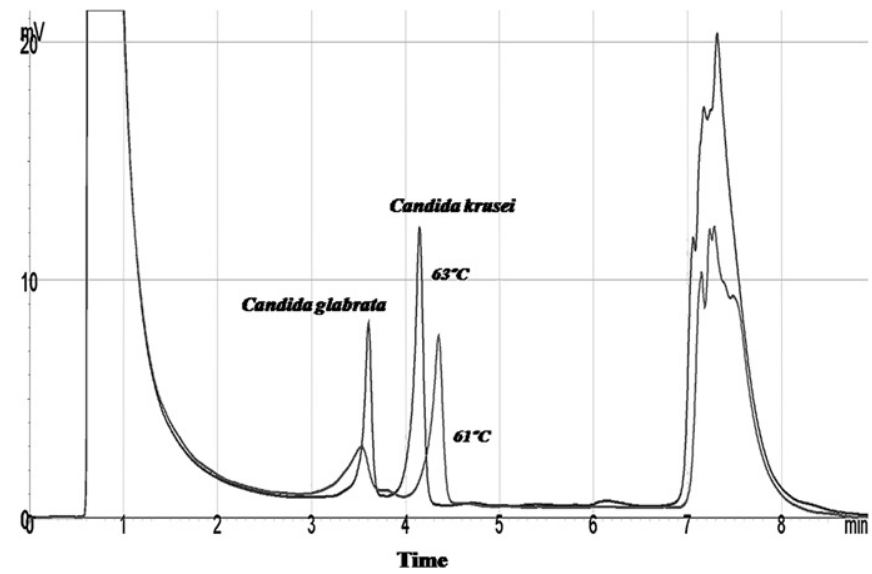

Fig. 11. DHPLC chromatogram of a mixture of two yeasts. The run was performed at $61{ }^{\circ} \mathrm{C} / 55 \% \mathrm{~B}$ and $63{ }^{\circ} \mathrm{C} / 54 \% \mathrm{~B}$ at an $0.9 \mathrm{ml} \mathrm{min}{ }^{-1}$ rate of flow. The first peak, collected at minute 3.5 at $63{ }^{\circ} \mathrm{C}$, corresponds to Candida glabrata, and the second peak, collected at minute 4.1 , again at $63{ }^{\circ} \mathrm{C}$, corresponds to Candida krusei. 


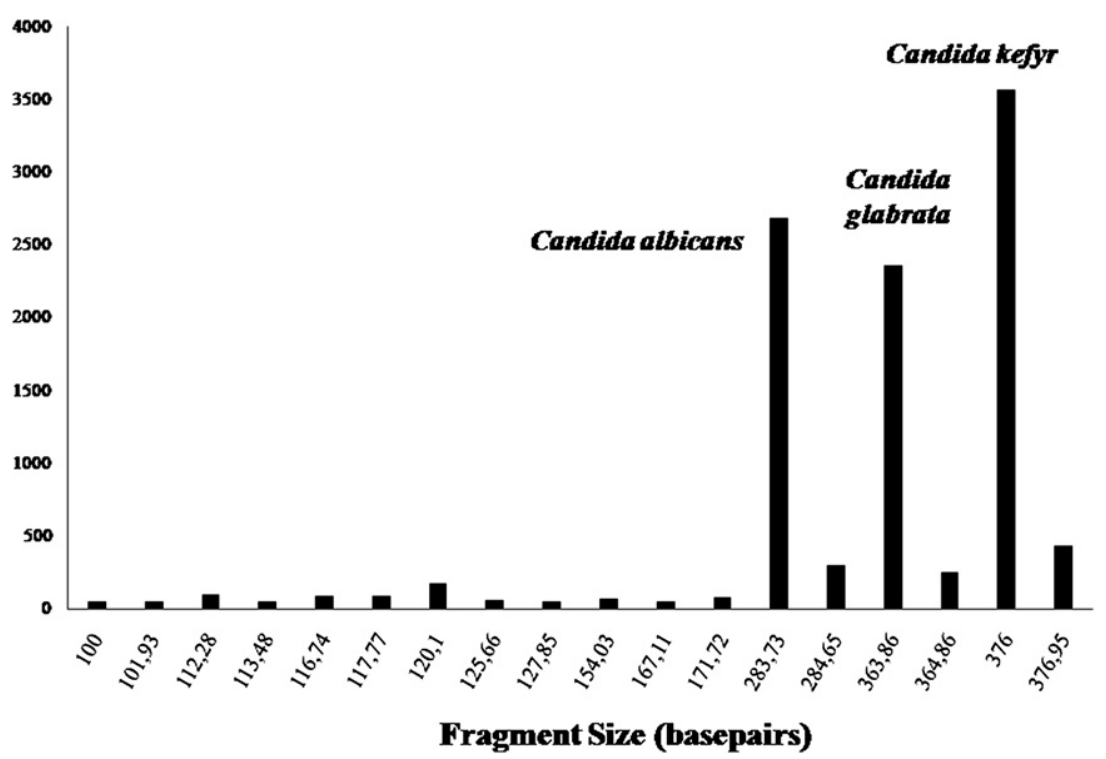

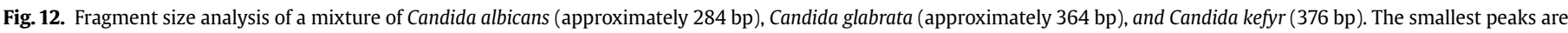

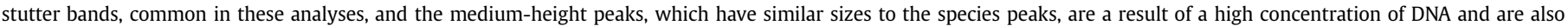
common. Normally, only the highest peak is considered.

as Chaetomium spp., Stemphylium spp., Trichoderma spp., Mucor spp., or Rhizopus spp., to name just a few, are known agents of erosion and staining, and they can alter the mechanical/structural characteristics of paper (Mandrioli and Caneva, 1998).

\subsection{DHPLC protocol}

As stated earlier, the number of fungi in any given sample is much greater than the number that can be grown in a culture media identified. This number can even amount to $100 \%$, since we have been able to detect through molecular biology methods (D2 region amplification and sequencing) fungi such as Eurotium halophilicum in an otherwise clean sample since there was no growth in any of the media tested. This species is extremely xerophilic, requiring only minor amounts of free water to develop. It is unable to grow at $\mathrm{a}_{\mathrm{w}}$ above 0.94 and even in optimal conditions presents a very slow growth rate (Arora et al., 1991). In our case, it was present in a paper from a photographic album from the nineteenth century.

Although the identification process is still underway, our data suggest that in $56 \%$ of negative cultures there is retrievable fungal DNA present and this DNA can represent more than one species. This rate will be updated as more samples are analyzed.

Figs. 9 and 10 correspond to a swab sample collected from a document showing several green/brown patches. The cultures showed no growth in any of the media tested but the molecular biology protocol definitely showed the presence of fungal DNA. The first DHPLC run consisted of a non-denaturing program to collect the peak formed between minute 13 and minute 14 . After peak collection a new program was tested, this time at partially denaturing temperatures, and after a new peak collection and sequencing it was possible to identify $A$. versicolor as a contaminant of this document (Fig. 10).

The DHPLC protocol was also used in association with the AFCE system. Before Candida krusei was introduced in the database a yeast sample mixture collected from an archival surface (a transport tray for books) with a swab and inoculated in MEA presented a dubious result in the fragment analyses as one of the peaks could be easily attributed to Candida glabrata but the other yeast presented an ITS2 length not yet contemplated in the database. Genomic D2 region amplification was performed and the amplified fragments were submitted to a temperature behavior study in the DHPLC. Fig. 11 shows the chromatogram obtained with $61{ }^{\circ} \mathrm{C}$ and $63{ }^{\circ} \mathrm{C}$.

At $63{ }^{\circ} \mathrm{C}$ (when the resolution was best), the peaks were collected at $3.5 \mathrm{~min}$ and $4.1 \mathrm{~min}$. After sequencing the authors could attribute the first peak to $C$. glabrata and the second to $C$. krusei. The ITS2 fragment size obtained in the first study was then attributed to this yeast and inserted in the database for further use.

\subsection{Automated fluorescent capillary electrophoresis system}

The ITS2 length database being created for the yeasts grown in the culture media has to be able to provide a clear identification of the species present, and the values cannot be altered by the presence of more than one fungus.

When mixed and run together the reference size was kept, allowing for the identification of each of the individual components (see Fig. 12) with only a minor difference to the individual analysis of each component. Therefore we can conclude that this method can be effectively used to discriminate the individuals in a mixture.

In the future, the development of this method for the identification of yeasts present in a mixture can be used for complex matrices other than paper or the surfaces tested here, namely in the analysis of soil and beach sand samples.

\section{Conclusions}

The protocol developed and presented here - which makes use of traditional culturing methods and two distinct molecular biology approaches - is proving to be capable of delivering important results both in terms of public health and heritage conservation. Although the method still needs to be further refined for general application, it is very promising.

Regarding DHPLC, certain combinations of DNA from different fungal species may need adjustment of conditions for optimal separation. However, in our study, as more samples were processed, the $50{ }^{\circ} \mathrm{C} / 40 \% \mathrm{~B}$ sizing program followed by a DSSF program 
at $59{ }^{\circ} \mathrm{C} / 55 \% \mathrm{~B}$ approach seemed to be the most fruitful for most separations. From this point on further temperatures $\left(61\right.$ or $\left.63^{\circ} \mathrm{C}\right)$ can be tested. The process of comparing both regions of interest ITS2 and D2 - is also underway.

As for the AFCE, the database being created and tested can be of great use for the identification of Candida and other yeast infections in humans when the biochemical assay is inconclusive or there is more than species in the culture media. As such, the usefulness of this protocol goes beyond its current application in air quality evaluation in archives as it is being studied as a possible substitute for the biochemical assay nowadays performed in the National Institute of Health.

Regarding air quality standards, this first sampling season has already been the basis for some behavioral changes as DNA of possible toxinogenic and pathogenic fungi have been found and identified.

The molecular biology protocols presented here have proven valuable as they have been able to pinpoint the presence of fungi when culture techniques were unable to produce colonies, and both methods are expandable to other areas where a mixed population is still an issue and an important setback for the genomic identification of fungal presence.

\section{Acknowledgements}

This work has the financial support of the Fundação para a Ciência e Tecnologia (SFRH/BD/36005/2007).

\section{References}

Abliz, P., Fukushima, K., Takizawa, K., Nishimura, K., 2004. Identification of pathogenic dematiceous fungi and related taxa based on large subunit ribosomal D1/D2 domain sequence analysis. FEMS Immunology and Medical Microbiology 40, 41-49.

Arora, D., Mukerji, K., Helmer, M. (Eds.), 1991, Handbook of Applied Mycology: Foods and Feeds, Vol. 3. Marcel Dekker Inc, New York.

Barlaan, E.A., Sugimori, M., Furukawa, S., Takeuchi, K., 2005. Profiling and monitoring of microbial populations by denaturing high-performance liquid chromatography. Journal of Microbiological Methods 61, 399-412.

Buttner, M.P., Stetzenbach, L.D., 1993. Monitoring airborne fungal spores in an experimental indoor environment to evaluate sampling methods and the effects of human activity on air sampling. Applied and Environmental Microbiology 59, 219-226.

Cano, J., Guarro, J., Gené, J., 2004. Molecular and morphological identification of Colletotrichum species of clinical interest. Journal of Clinical Microbiology 42, 2450-2454.

Corte, A.M., Ferroni, A., Salvo, V.S., 2003. Isolation of fungal species from test samples and maps damaged by foxing, and correlation between these species and the environment. International Biodeterioration \& Biodegradation 51, 167-173.

De Baere, T., Claeys, G., Swinne, D., Massonet, C., Verschraegen, G., Muylaert, A., Vaneechoutte, M., 2002. Identification of cultured isolates of clinically important yeast species using fluorescent fragment length analysis of the amplified internally transcribed rRNA spacer 2 region. BMC Microbiology 2, 21.

Domann, E., Hong, G., Imirzalioglu, C., Turschner, S., Kuhle, J., Watzel, C., Hain, T., Hossein, H., Chakraborty, T., 2003. Culture-independent identification of pathogenic bacteria and polymicrobial infections in the genitourinary tract of renal transplant recipients. Journal of Clinical Microbiology 41, 5500-5510.

Duchaine, C., Mériaux, A., 2001. The importance of combining air sampling and surface analysis when studying problematic houses for mold biodiversity determination. Aerobiologia 17, 121-125.

Fujita, S.I., Senda, Y., Nakaguchi, S., Hashimoto, T., 2001. Multiplex PCR using internal transcribed spacer 1 and 2 regions for rapid detection and identification of yeast strains. Journal of Clinical Microbiology 39, 3617-3622.
Gafan, G.P., Spratt, D.A., 2005. Denaturing gradient gel electrophoresis gel expansion (DGGEGE) - an attempt to resolve the limitations of co-migration in the DGGE of complex polymicrobial communities. FEMS Microbiology Letters 253 . 303-307.

Gelsomino, A., Keijzer-Wolters, A.C., Cacco, G., van Elsas, J.D., 1999. Assessment of bacterial community structure in soil by polymerase chain reaction and denaturing gradient gel electrophoresis. Journal of Microbiological Methods 38, 1-15.

Goldenberg, O., Herrmann, S., Adam, T., Marjoram, G., Hong, G., Gobël, U.B., Graf, B., 2005. Use of denaturing high-performance liquid chromatography for rapid detection of seven Candida species. Journal of Clinical Microbiology 43, 5912-5915.

Goldenberg, O., Herrmann, S., Marjoram, G., Noyer-Weidner, M., Hong, G., Bereswill, S., Göbel, U., 2007. Molecular monitoring of the intestinal flora by denaturing high performance liquid chromatography. Journal of Microbiological Methods 68, 94-105.

Hinrikson, H., Hurst, S.F., Lott, T.J., Warnock, D.W., Morrison, C.J., 2005. Assessment of ribosomal large-subunit D1-D, internal transcribed spacer 1 , and internal transcribed spacer 2 regions as targets for molecular identification of medically important Aspergillus species. Journal of Clinical Microbiology 43, 2092-2103.

Janse, I., Bok, J., Zwart, G., 2004. A simple remedy against artifactual double bands in denaturing gradient gel electrophoresis. Journal of Microbiological Methods 57, 279-281.

Kemp, P.C., Neumeister-Kemp, H.G., Esposito, B., 2003. Changes in airborne fungi from the outdoors to indoor air: large HVAC systems in nonproblem buildings in two different climates. American Industrial Hygiene Association Journal 64, 269-275.

Larone, D.H., 2002. Medically important fungi: A guide to identification, fourth ed. American Society for Microbiology, Washington.

Leaw, S.N., Chang, H.C., Sun, H.F., Barton, R., Bouchara, J.P., Chang, T.C., 2006. Identification of medically important yeast species by sequence analysis of the internal transcribed spacer regions. Journal of Clinical Microbiology 44, 693-699.

Mandrioli, P., Caneva, G., 1998. Aerobiologia e beni culturali; associazione Italiana di aerobiologia - Consiglio nazionale delle richerche. Nardini Editore, Firenze.

Maggi, O., Persiani, A.M., Gallo, F., Valenti, P., Pasquariello, G., Sclocchi, M.C., Scorrano, M., 2000. Airborne fungal spores in dust present in archives: proposal for a detection method, new for archival materials. Aerobiologia 16, 429-434.

Muyzer, G., Smalla, K., 1998. Application of denaturing gradient gel electrophoresis (DGGE) and temperature gradient gel electrophoresis (TGGE) in microbial ecology. Antonie van Leeuwenhoek 73, 127-141.

Nikolausz, M., Sipos, R., Revesz, S., Szekely, A., Marialigeti, K., 2005. Observation of bias associated with re-amplification of DNA isolated from denaturing gradient gels. FEMS Microbiology Letters 244, 385-390.

Ninet, B., Jan, I., Bontems, O., Léchenne, B., Jousson, O., Panizzon, R., Lew, D. Monod, M., 2003. Identification of dermatophyte species by $28 \mathrm{~S}$ ribossomal DNA sequencing with a commercial kit. Journal of Clinical Microbiology 41, 826-830.

Nota Técnica NT-SCE-02, 2009. Metodologia para auditorias periódicas de QAI em edifícios existentes no Âmbito do RSECE. http://www.apambiente.pt/politicasambiente/Ar/QualidadeArInterior/AuditoriasRequisitosQAI/Documents/ NT_SCE_Abril_2009.pdf.

Rossman, A., 2007. Report of the planning workshop for all fungi DNA barcoding. Inoculum 58, 1-5.

Salvaggio, J., Aukrust, L., 1981. Mould induced asthma. Journal of Allergy and Clinical Immunology 68, 327-346.

Samson, R.A., Hoekstra, E.S., Frisvad, J.C., 2004. Introduction to food- and airborne fungi, seventh ed. Centraalbureau voor Schimmelcultures, Utrecht.

Turenne, C.Y., Sanche, S.E., Hoban, D.J., Karlowski, J.A., Kabani, A.M., 1999. Rapid identification of fungi by using the ITS2 genetic region and an automated fluorescent capillary electrophoresis system. Journal of Clinical Microbiology 37 , 1846-1851.

White, T.J., Bruns, T., Lee, S., Taylor, J., 1990. Amplification and direct sequencing of fungal ribossomal RNA genes for phylogenetics. In: Innis, M.A., Gelfand, D.H., Sninsky, J.J., White, T.J. (Eds.), PCR protocols: A guide to methods and applications. Academic Press, San Diego.

Wlazlo, A., Lawniczek, A., Ludzen-Izbinska, B., Harkawy, A., Anczyk, E., Gorny, R.L., 2008. Exposure to bioaerosols at libraries. Indoor Air 17-22 August 2008, Copenhagen, Denmark, Paper ID:499.

Zyska, B., 1997. Fungi isolated from library materials: a review of the literature. International Biodeterioration \& Biodegradation 40, 43-51. 